\title{
ENERGIA IONIZANTE NA CONSERVAÇÃO DE ALIMENTOS: REVISÃO
}

\author{
TARCÍSIO LIMA FILHO * \\ LUCIANO JOSÉ QUINTÃO TEIXEIRA ** \\ CAROLINA TATAGIBA DA ROCHA * \\ GLAUCIA APARECIDA MATAVELI FERREIRA *** \\ MICHELLE CARVALHO DE SOUZA ****
}

\begin{abstract}
Efetuou-se revisão de literatura sobre a utilização da radiação ionizante como forma de conservação de alimentos. Foram abordados tópicos como sua evolução histórica, o princípio de funcionamento dos equipamentos, suas diferentes áreas de aplicação e, principalmente, sua utilização na conservação de alimentos. São apresentados os resultados de estudos realizados com o objetivo de verificar a eficiência da radiação ionizante na eliminação de vários micro-organismos em diversos produtos e o efeito da radiação ionizante nas características sensoriais e nutricionais dos alimentos. Apesar de já ter sido comprovada a segurança da aplicação da radiação ionizante em alimentos, da sua utilização ser permitida em diversos países e de ser cientificamente aceita como excelente método de conservação de alimentos, o progresso no seu uso comercial tem sido lento face às interpretações errôneas dos consumidores e à falta de informações sobre o uso dessa tecnologia.
\end{abstract}

PALAVRAS-CHAVES: CONSERVAÇÃO DE ALIMENTOS; RADIAÇÃO IONIZANTE; TRATAMENTO NÃO TÉRMICO.

* Engenheiro de Alimentos, Mestrando em Ciência e Tecnologia de Alimentos, Centro de Ciências Agrárias (CCA), Universidade Federal do Espírito Santo (UFES), Alegre, ES (e-mail: tarcisiolimafilho@hotmail.com; caroltatagiba@hotmail.com).

** Doutor em Ciência e Tecnologia de Alimentos, Professor, Departamento de Engenharia de Alimentos, UFES, Alegre, ES (e-mail: Iuqteixeira@yahoo.com.br).

*** Farmacêutica, Mestranda em Ciência e Tecnologia de Alimentos, UFES, Alegre, ES (e-mail: glauciamataveli@ibest.com.br).

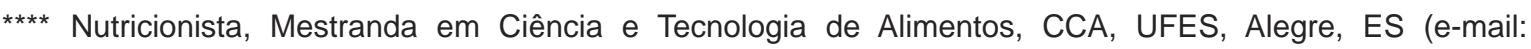
michellesouza.nutricao@hotmail.com). 


\section{INTRODUÇÃo}

Tem sido verificada crescente procura dos consumidores por alimentos com características mais próximas das naturais, além de maior preocupação com a qualidade e segurança alimentar. Os métodos térmicos de processamento são formas eficientes de se promover a estabilidade dos alimentos, porém apresentam as desvantagens de provocar alterações sensoriais e nutricionais indesejáveis em alguns produtos. Nesse contexto, surgiram os tratamentos não térmicos de alimentos, objetivando a obtenção de produtos seguros e a manutenção do sabor, da cor, do aroma, da textura e dos nutrientes dos alimentos, quando comparados aos similares processados termicamente (ZHONG et al., 2005).

A radiação ionizante, técnica de processamento não térmico, vem sendo aplicada com diversos propósitos. Destaca-se a sua aplicação em alimentos, área em que se tornou promissora técnica de conservação em combinação ou substituição ao tratamento térmico. Quando doses controladas são administradas, as alterações nas características nutricionais e sensoriais do alimento são mínimas. Além disso, pode ser aplicada em alimentos sólidos e líquidos já embalados, evitando a recontaminação pós tratamento (HERNANDES, VITAL e SABAA SRUR, 2003; FELLOWS, 2006).

Define-se radiação como a emissão e a propagação da energia ou partículas através do espaço e da matéria. As radiações com comprimento de ondas mais curto, principalmente os raios gama, partículas beta, partículas alfa, raios $X$ e raios cósmicos apresentam maior eficiência na conservação de alimentos por serem mais nocivas aos micro-organismos (FRANCO e LANDGRAF, 2008).

As radiações ionizantes impedem a divisão de células vivas como bactérias, fungos e organismos superiores, pois alteram suas estruturas moleculares e induzem modificações bioquímicas nos processos fisiológicos dos tecidos de alguns vegetais, retardando a sua maturação, envelhecimento e brotamento (STEFANOVA, VASILEV e SPASSOV, 2010). São bastante eficazes contra insetos e ácaros na desinfestação de frutas e hortaliças (FOLLETTI e ARMSTRONG, 2004; FELLOWS, 2006) e podem satisfazer as exigências das barreiras fitossanitárias impostas por países importadores, possibilitando o ganho de novos mercados (STEFANOVA, VASILEV e SPASSOV, 2010; MOSTAFAVI, MIRMAJLESSI e FATHOLLAHI, 2012). Embora também possam causar a inativação de enzimas, as doses utilizadas na irradiação de alimentos não são suficientes para inativá-las (FRANCO e LANDGRAF, 2008).

Neste trabalho de revisão de literatura sobre a utilização da radiação ionizante como forma de conservação de alimentos foram abordados os aspectos históricos, fundamentos teóricos, aplicações em outras áreas, ressaltando-se os efeitos da radiação ionizante sobre os micro-organismos, características sensoriais e nutricionais dos alimentos, além de suas principais limitações e desafios.

\section{EVOLUÇÃO HISTÓRICA}

Embora a irradiação de alimentos pareça ser tecnologia recente, as pesquisas se iniciaram com a descoberta do raio X por Roentgen em 1895, e da radioatividade por Bercquerel em 1896. Já em 1905 surgiu a primeira patente sobre tratamento de alimentos, principalmente de cereais, com raios alfa, beta e gama oriundos de substância radioativa. Schwartz, do Departamento de Agricultura dos Estados Unidos da América (EUA), sugeriu a utilização de raios $\mathrm{X}$ em carne de porco para inativação de triquinas em 1921 (DIEHL, 2002).

Nos EUA, durante a década de 50, foi lançada a campanha "Átomos para Paz" para mostrar ao mundo os benefícios da energia atômica. À partir desse programa foram fomentados estudos na área de irradiação de alimentos, tendo o Departamento Médico das Forças Armadas Americanas sido pioneiro nessas pesquisas. Outros países também efetuaram estudos nessa área, como a 
França, a Alemanha, o Canadá e a União Soviética (DIEHL, 2002).

Em 1957, na Alemanha, ocorreu a primeira utilização comercial da irradiação de alimentos, quando uma indústria de especiarias empregou feixe de elétrons para melhorar a qualidade higiênica de seus produtos. No entanto, vários órgãos de saúde de diversos países ainda hesitavam em conceder permissão para comercialização de produtos irradiados. A inexistência de estudos mais aprofundados representava o principal obstáculo para a utilização comercial da irradiação de alimentos (DIEHL, 2002).

Várias pesquisas e seus resultados foram avaliados pelo Comitê Misto de Especialistas em Irradiação de Alimentos (CMEIA), convocado pela Food Agriculture Organization (FAO), pela Agência Internacional de Energia Atômica (IAEA) e pela Organização Mundial de Saúde (OMS). Esse Comitê concluiu, em 1980, que a irradiação de qualquer alimento não apresenta riscos toxicológicos, problemas microbiológicos ou nutricionais, desde que respeitada a dose limite de 10 KGy (WHO, 1981). Com base nessa afirmação, o Codex Alimentarius Commision adotou, em 1983, padrões mundiais quanto à irradiação de alimentos para proteger a saúde do consumidor e facilitar o mercado internacional. A partir de então, só tem aumentado o número de países que permitem o uso de irradiação de alimentos (DIEHL, 2002).

Em 1997, grupo de estudo composto por representantes da FAO, IAEA e OMS examinaram os resultados obtidos com a irradiação de alimentos em doses acima de $10 \mathrm{KGy}$. Foi observado que poucos alimentos toleram doses acima de $10 \mathrm{KGy}$ sem perda de qualidade. Por outro lado, testes utilizando doses de até $70 \mathrm{KGy}$ em alimentos para animais não demonstraram acarretar danos à saúde. Para o referido grupo de estudo, alimentos irradiados com qualquer dose adequada para se atingir o objetivo tecnológico são seguros e nutricionalmente adequados (WHO, 1999).

Apesar de inúmeros estudos comprovarem a segurança da irradiação de alimentos, essa tecnologia sofreu oposição de grupos de ativistas e de pessoas receosas quanto ao consumo de alimentos irradiados, principalmente na União Europeia, o que diminuiu sua utilização pelas indústrias (DIEHL, 2002). Até 2002, no entanto, 42 países já haviam aprovado a utilização da irradiação em grande variedade de alimentos (DIEHL, 2002). Em 2011, mais de 60 países contavam com regulamentos que permitem a irradiação de pelo menos um alimento (FAO/IAEA, 2011). O Brasil está incluído nessa estatística, destacando-se as especiarias e temperos vegetais secos como os alimentos mais comumente irradiados. A ANVISA aprovou, mediante a RDC n. 21 de 26 de janeiro de 2001, regulamento técnico para irradiação de alimentos, estabelecendo que qualquer alimento pode ser tratado por radiação desde que a dose mínima absorvida seja suficiente para atender a finalidade pretendida e a dose máxima absorvida seja inferior àquela que comprometeria as propriedades funcionais e ou os atributos sensoriais do alimento, não sendo estipulado valor numérico máximo para a dose permitida (BRASIL, 2001).

Apesar da aprovação e do controle do emprego da irradiação, diversas barreiras ainda persistem e impedem que os alimentos irradiados alcancem completa comercialização. Na verdade, não são barreiras de natureza técnica ou científica, mas relacionadas ao custo inicial de sua utilização e de aceitação pelo consumidor. Assim, apesar de cientificamente aceito como excelente método de conservação de alimentos, o progresso comercial da irradiação tem sido lento. Interpretações errôneas dos consumidores, que acham difícil avaliar os benefícios dessa técnica de processamento e a falta de informações ainda limitam o uso dessa tecnologia (ORNELLAS et al., 2006).

\section{DEFINIÇÕES E PRINCÍPIOS DE FUNCIONAMENTO DOS EQUIPAMENTOS}

A irradiação de alimentos, processo físico de tratamento, baseia-se em submeter o produto já embalado ou a granel a doses controladas de radiação ionizante com finalidade sanitária, fitossanitária e ou tecnológica (BRASIL, 2001).

A radiação ionizante é transmitida por partículas de alta energia (alfa, prótons, elétrons 
e nêutrons) ou ondas eletromagnéticas (raios $X$ e raios gama) que apresentam energia suficiente para remover elétrons de valência de um átomo e energia inferior ao limiar das reações nucleares. Das diversas formas de radiação ionizante, apenas duas são utilizadas na irradiação de alimentos: radiação eletromagnética, principalmente a gama e raios $\mathrm{X}$, e a radiação por feixe de elétrons. Enquanto a radiação eletromagnética se propaga na forma de ondas, a radiação por emissão de elétrons (corpuscular) baseia-se na transmissão de energia pela aceleração dos elétrons (BRASIL, 2001; GRANDISON, 2006; CENA, 2011).

De acordo com a ANVISA (BRASIL, 2001), as fontes de radiação autorizadas pela Comissão Nacional de Energia Nuclear são: isótopos radioativos emissores de radiação gama, como o Cobalto 60 e Césio 137; raios $X$ gerados por equipamentos que trabalham com energia de até $5 \mathrm{MeV}$; e elétrons gerados por máquinas com energia de até $10 \mathrm{MeV}$.

Segundo Fellows (2006), os equipamentos de irradiação são compostos pela fonte de radiação (fonte de isótopo) de alta energia para produzir raios gama ou, com menor frequência, por máquina emissora de feixes de elétrons de alta energia.

As fontes de radiação gama mais utilizadas pela maioria das usinas comerciais são o cobalto 60 e o césio 137. Essas fontes de isótopos não podem ser desligadas, razão pela qual são mantidas blindadas em tanque de água localizado abaixo da área de processo para permitir a aproximação do operador da máquina. Quando o irradiador está em funcionamento ocorre a elevação da fonte, sendo o alimento embalado transportado por esteira automática através do campo de irradiação em rota circular que permite maior uniformidade e eficiência do processo (FELLOWS, 2006).

As máquinas emissoras de feixes de elétrons podem ser desligadas, sendo constituídas de um cátodo aquecido para fornecer elétrons e um tubo com vácuo, no qual os elétrons são acelerados por campo eletrostático de alta voltagem. Os feixes de elétrons são emitidos diretamente no alimento ou em material adequado para produção de raio X (FELLOWS, 2006).

\section{APLICAÇÕES DA RADIAÇÃO IONIZANTE}

Desde a descoberta do raio $X$ e da radioatividade, além da conservação de alimentos, diversos segmentos da indústria, da agricultura, da medicina e da ciência têm utilizado a radiação ionizante visando a melhoria da qualidade de vida da população e o desenvolvimento tecnológico. As características específicas de cada tipo de radiação ionizante são determinantes para a definição da área em que será aplicada como, por exemplo, agricultura, indústria e medicina (PINO e GIOVEDI, 2005).

Industrialmente, a radiação ionizante é utilizada no beneficiamento de pedras preciosas e de materiais poliméricos, esterilização de materiais hospitalares, cura de tintas e vernizes e em alimentos. Na agricultura é utilizada como tratamento sanitário e fitossanitário e na hidrólise de fibras celulósicas e bagaços de cana. A utilização da radiação ionizante na medicina está relacionada com o diagnóstico e a terapia de doenças. Devido a essas inúmeras aplicações, é crescente o número de linhas de pesquisas que estudam a utilização da radiação ionizante nesses diferentes segmentos (CNEN, 2012).

A utilização experimental da radiação ionizante no tratamento de pedras preciosas iniciou com a descoberta da radiação, já sua aplicação comercial começou por volta de 1940 (ASHBAUGH, 2011). Ao irradiar a pedra, deslocam-se elétrons dos precursores de lacuna, aumentando a possibilidade de se ionizar os centros de cor existentes no retículo cristalino e permitindo a formação de novas combinações de ligações, as quais alteram ou geram os centros de cor do cristal. A cor produzida pelo centro de cor pode variar de intensidade e de tonalidade de acordo com a orientação cristalográfica (ASHBAUGH, 2011). Esse processo resulta em produto com maior valor agregado, tendo em vista que o preço do diamante-fantasia, cuja cor foi modificada, é sempre maior que o seu correspondente incolor (SVIZZERO, 2006).

A irradiação tem sido utilizada na preservação do patrimônio histórico e cultural mundial 
por meio da eliminação de fungos e bactérias que deterioram livros, documentos e obras de arte das bibliotecas e museus. No âmbito cultural, essa técnica também pode ser estendida a desenhos, fotografias e peças arqueológicas, entre outras coleções (BRASIL, 2005). A irradiação apresenta vantagens sobre os processos químicos, como a menor manipulação e menores riscos à saúde dos leitores e admiradores pela ausência de contato com produtos tóxicos (BRASIL, 2005).

$\mathrm{Na}$ agricultura, a radiação ionizante vem sendo aplicada em fibras celulósicas ou em bagaços de cana-de-açúcar, visando maior digestibilidade e palatabilidade desses resíduos para sua utilização em ração animal. A irradiação, por feixe de elétrons, de bagaço de cana possibilitou aumento de cerca de $40 \%$ no rendimento da hidrólise enzimática da celulose, quando utilizada dose absorvida de 30 KGy (CARDOSO, 2008). Vitti et al. (1998) também observaram aumento da digestibilidade do bagaço da cana submetido à feixes de elétrons, afirmando que a utilização de biomassa irradiada como complemento na ração de ruminantes é promissora.

Existem vários estudos da aplicação da radiação ionizante na desinfestação de frutas em substituição aos fumigantes, sendo bastante eficaz contra insetos e ácaros em doses que não afetam sua qualidade (FOLLETTI e ARMSTRONG, 2004). Segundo Moy et al. (1983), a irradiação apresenta vantagens sobre os métodos de tratamento com produtos químicos e térmicos, como: maior eficiência, assegurando a desinfestação total das frutas; maior facilidade de aplicação por tratar-se de processo contínuo; inexistência de resíduos nas frutas e aumento da vida-de-prateleira, devido ao retardamento do amadurecimento das frutas climatéricas. Além disso, a irradiação pode auxiliar na conquista de novos mercados para exportadores de frutas, assegurando a aceitação do produto em barreiras fitossanitárias cada vez mais rígidas (STEFANOVA, VASILEV e SPASSOV, 2010; MOSTAFAVI, MIRMAJLESSI e FATHOLLAHI, 2012).

A irradiação tem sido utilizada em substituição ao uso de produtos químicos e tratamentos térmicos no processamento de polímeros, apresentando diferentes finalidades dependendo do tipo de polímero (PINO e GIOVEDI, 2006). A irradiação induz reações de reticulação ou de degradação, simultaneamente, e sempre uma delas prevalece sobre a outra. A reticulação melhora as propriedades químicas, físicas e mecânicas do material, já a segunda resulta na degradação do material podendo levar à sua completa destruição (GIOVEDI et al., 2005). Como exemplo de melhoria das propriedades dos polímeros devido às reações de reticulação tem-se o aumento da durabilidade e do grau de segurança de pneus, cujas lâminas de borracha das partes laterais foram irradiadas. Outras aplicações da reticulação incluem fios e cabos elétricos nas indústrias automobilística, eletroeletrônica e aeronáutica e materiais utilizados na produção de tubulações de água quente na construção civil (visando à melhoria das propriedades de isolante térmico do material irradiado), garantindo sua utilização em altas temperaturas (CHMIELEWSKI, HAJI-SAIED e AHMED, 2005).

As reações de degradação causadas pela irradiação têm sido utilizadas na reciclagem de resíduos poliméricos, contribuindo para a preservação do meio ambiente. Altas doses de irradiação podem converter celulose em açúcar e resíduos de borracha butílicas em óleos lubrificantes. Entretanto, a maior utilização industrial da irradiação em polímeros ocorre em resíduos de teflon, transformando-os em pó a ser empregado pela indústria de tintas e lubrificantes (CLOUGH, 2001). Outra aplicação industrial envolve a produção de hidrogeis para a área médica, os quais são constituídos de água e de polímero reticulado e insolúvel. Esses materiais são utilizados no tratamento de queimaduras e diferentes tipos de lesões na pele, diminuindo a dor e o tempo de cicatrização (IPEN, 2012a).

$\mathrm{Na}$ área da saúde, a radiação ionizante encontra aplicação no preparo de radiofármacos, substratos que contêm um átomo radioativo em sua estrutura. São utilizados no diagnóstico de doenças e tratamento do câncer de tireoide, hipertireoidismo e linfoma do tipo não-Hodgkin (ARAÚJO et al., 2008).

A radioterapia, tratamento do câncer utilizando radiação ionizante, baseia-se na ionização direta ou indireta dos átomos e moléculas do tecido tumoral, acarretando a destruição das células 
malignas. A radioterapia pode ser realizada de forma externa ou interna. A externa, denominada teleterapia, consiste em utilizar feixes de raio $X$, radiação gama ou elétrons de alta energia para irradiação do volume alvo localizado a 1 metro de distância. Já na interna, denominada braquiterapia, as fontes de radiação encapsuladas geram radiação a poucos centímetros dos tumores (BRASIL, 2008).

Além da esterilização de diversos materiais descartáveis (como luvas, seringas, agulhas, gaze, algodão e mascaras cirúrgica) (IPEN, 2012b), emprega-se a irradiação em tecidos biológicos utilizados em transplantes para minimizar a imunogenicidade, eliminar micro-organismos e reduzir o risco de transferir doenças contagiosas, garantindo a qualidade e a segurança dos pacientes (IPEN, 2012c).

\section{RADIAÇÃO IONIZANTE NA CONSERVAÇÃO DE ALIMENTOS}

\subsection{EFEITO SOBRE MICRO-ORGANISMOS}

A radiação de alimentos produz íons reativos que alteram a estrutura da membrana celular e afeta a atividade de enzimas metabólicas, danificando ou eliminando os micro-organismos. Entretanto, o efeito mais significante ocorre no DNA e nas moléculas de ácido ribonucleico no núcleo das células, fundamentais para o crescimento e reprodução dos micro-organismos (FELLOWS, 2006).

A eficiência do tratamento sobre os micro-organismos depende de vários fatores como: o número de micro-organismos (quanto maior a quantidade de micro-organismos presentes no alimento maior será a dose de irradiação exigida); a composição do alimento (micro-organismos em meios ricos em proteínas são mais resistentes do que em solução tampão); a presença ou ausência de oxigênio (a presença de oxigênio torna os micro-organismos menos resistentes à radiação); estado físico dos alimentos (células desidratadas ou congeladas são mais resistentes à radiação do que no estado normal); a condição do micro-organismo (micro-organismos na fase lag são mais resistentes) e a radiorresistência do micro-organismo (no geral, quanto mais complexo (maior) o DNA maior a sensibilidade dos micro-organismos à irradiação), conforme demonstrado na Tabela 1 (FELLOWS, 2006; FRANCO e LANDGRAF, 2008).

Como pode ser observado na Tabela 1 , a dose limite de $10 \mathrm{KGy}$ recomendada pela CMEIA elimina a maioria das bactérias, mas não apresenta tanto efeito sobre esporos e vírus.

\section{TABELA 1 - DOSE LETAL DE RADIAÇÃO PARA} ALGUNS SERES VIVOS

\begin{tabular}{lc}
\hline Organismo & Dose letal (Gy) \\
\hline Mamífero & $5-10$ \\
\hline Insetos & $10-1000$ \\
\hline Bactérias & $500-10000$ \\
\hline Esporos & $10000-50000$ \\
\hline Vírus & $10000-200000$ \\
\hline
\end{tabular}

Fonte: HERNANDES, VITAL e SABAA SRUR (2003).

Semelhante à destruição térmica, a sensibilidade do micro-organismo à radiação pode ser expressa como o valor $\mathrm{D}_{10}$, a dose necessária para eliminar $90 \%$ da população inicial de microorganismos (FELLOWS, 2006). Na Tabela 2 estão apresentados os valores $D_{10}$ para alguns microorganismos patogênicos. 
TABELA 2 - VALORES $D_{10}$ DE ALGUNS MICRO-ORGANISMOS PATOGÊNICOS

\begin{tabular}{|c|c|c|c|c|}
\hline Micro-organismo & Meio & $\begin{array}{l}\text { Temperatura de } \\
\text { radiação }\left({ }^{\circ} \mathrm{C}\right)\end{array}$ & Valor D (Gy) & Ref. \\
\hline Aeromonas hydrophila & Carne bovina & 2 & $140-190$ & 2417 \\
\hline Bacillus cereus & $\begin{array}{l}\text { Caldo nutriente } \\
\text { Costela marinada } \\
\text { Peixe }\end{array}$ & $\begin{array}{c}25 \\
\text { Refrigerada } \\
0-2\end{array}$ & $\begin{array}{c}3200 \\
595 \\
150-250\end{array}$ & $\begin{array}{l}24 \\
32 \\
33\end{array}$ \\
\hline Campylobacter jejuni & $\begin{array}{l}\text { Carne bovina } \\
\text { Carne moída bovina (pouca gordura) } \\
\text { Carne moída bovina (muita gordura) }\end{array}$ & $\begin{array}{c}2-4 \\
4 \\
4\end{array}$ & $\begin{array}{c}180 \\
175 \\
178-199\end{array}$ & $\begin{array}{l}17 \\
10 \\
10\end{array}$ \\
\hline $\begin{array}{l}\text { Clostridium botulinum } \\
\text { (esporos) }\end{array}$ & Carne de frango & -30 & 3560 & 17 \\
\hline $\begin{array}{l}\text { Clostridium botulinum } \\
\text { E-Alaska }\end{array}$ & Carne cozida & 25 & 1400 & 24 \\
\hline Enterobacter sakazakii & $\begin{array}{l}\text { Leite infantil em pó } \\
\text { Leite infantil reidratado }\end{array}$ & - & $\begin{array}{c}1060-1710 \\
240-370 \\
\end{array}$ & $\begin{array}{l}44 \\
44\end{array}$ \\
\hline $\begin{array}{l}\text { Escherichia coli } \\
\text { 0157:H7 }\end{array}$ & $\begin{array}{l}\text { Alface } \\
\text { Carne de frango } \\
\text { Frango desossado } \\
\text { Frango desossado } \\
\text { Frango desossado } \\
\text { Frango desossado } \\
\text { Carne de boi } \\
\text { Carne de boi } \\
\text { Carne moída bovina (pouca gordura) } \\
\text { Carne moída bovina (muita gordura) } \\
\text { Costela marinada } \\
\text { Hambúrguer } \\
\text { Hot dog Frankfurter } \\
\text { Pepino } \\
\text { Repolho } \\
\text { Sorvete de baunilha } \\
\text { Sorvete de chocolate } \\
\text { Sorvete de morango } \\
\end{array}$ & $\begin{array}{c}- \\
4-8 \\
0 \text { (ar) } \\
0 \text { (vácuo) } \\
5 \text { (vácuo) } \\
-5 \text { (vácuo) } \\
2-4 \\
0 \text { (vácuo) } \\
4 \\
4 \\
\text { Refrigerada } \\
5,6 \\
4 \text { (AM*) } \\
- \\
- \\
-72 \\
-72 \\
-72 \\
\end{array}$ & $\begin{array}{l}110-120 \\
720 \\
260 \\
270 \\
280 \\
440 \\
240 \\
270 \\
241 \\
251 \\
539 \\
170-270 \\
430-470 \\
190 \\
170 \\
310 \\
280 \\
380\end{array}$ & $\begin{array}{l}22 \\
51 \\
54 \\
54 \\
54 \\
54 \\
17 \\
54 \\
10 \\
10 \\
32 \\
8 \\
50 \\
34 \\
34 \\
31 \\
31 \\
31 \\
\end{array}$ \\
\hline Listeria ivanovii & $\begin{array}{l}\text { Sorvete de baunilha } \\
\text { Sorvete de chocolate } \\
\text { Sorvete de morango } \\
\end{array}$ & $\begin{array}{l}-72 \\
-72 \\
-72 \\
\end{array}$ & $\begin{array}{l}750 \\
770 \\
710 \\
\end{array}$ & $\begin{array}{l}31 \\
31 \\
31 \\
\end{array}$ \\
\hline $\begin{array}{l}\text { Listeria } \\
\text { monocytogenes }\end{array}$ & $\begin{array}{l}\text { Alface } \\
\text { Meio de cultura } \\
\text { carne de peito de frango } \\
\text { frango desossado } \\
\text { carne de boi moída crua } \\
\text { Peixe } \\
\text { Hot dog Frankfurter }\end{array}$ & $\begin{array}{c}4 \\
25 \\
25 \\
2-4 \\
25 \\
0-2 \\
4(\mathrm{AM})\end{array}$ & $\begin{array}{c}190-200 \\
364 \\
599 \\
270-770 \\
699 \\
200-300 \\
530-570\end{array}$ & $\begin{array}{l}41 \\
23 \\
23 \\
25 \\
23 \\
33 \\
50\end{array}$ \\
\hline Salmonella enteritidis & $\begin{array}{l}\text { Ovo inteiro } \\
\text { Ovo líquido }\end{array}$ & - & $\begin{array}{l}320-410 \\
270-380 \\
\end{array}$ & $\begin{array}{l}49 \\
49 \\
\end{array}$ \\
\hline Salmonella Paratyphi A & $\begin{array}{l}\text { Pepino } \\
\text { Repolho }\end{array}$ & $\begin{array}{l}- \\
-\end{array}$ & $\begin{array}{l}250 \\
290\end{array}$ & $\begin{array}{l}34 \\
34\end{array}$ \\
\hline $\begin{array}{l}\text { Salmonella } \\
\text { Typhimurium }\end{array}$ & $\begin{array}{l}\text { Sobrecoxas de frango } \\
\text { caldo tripticase soja } \\
\text { Costela marinada } \\
\text { Peixe }\end{array}$ & $\begin{array}{c}2 \text { - } 4 \\
- \\
\text { Refrigeração } \\
0-2 \\
\end{array}$ & $\begin{array}{l}240-480 \\
160-210 \\
637 \\
100-150 \\
\end{array}$ & $\begin{array}{l}47 \\
47 \\
32 \\
33 \\
\end{array}$ \\
\hline Salmonella spp. & $\begin{array}{l}\text { Alface } \\
\text { Alface } \\
\text { Carne moída bovina (pouca gordura) } \\
\text { Carne moída bovina (muita gordura) }\end{array}$ & $\begin{array}{l}- \\
4 \\
4 \\
4\end{array}$ & $\begin{array}{l}160-230 \\
230-310 \\
621-624 \\
618-661\end{array}$ & $\begin{array}{l}22 \\
41 \\
10 \\
10\end{array}$ \\
\hline
\end{tabular}


Continuação

\begin{tabular}{l|l|c|c|c}
\hline Micro-organismo & Meio & $\begin{array}{l}\text { Temperatura de } \\
\left.\text { radiação ( }{ }^{\circ} \mathbf{C}\right)\end{array}$ & Valor D (Gy) & Ref. \\
\hline Shigella dysenteriae & Camarão & Congelado & 220 & 24 \\
Staphylococcus aureus & Carne de frango & $4-8$ & 410 & 51 \\
& Carne de frango & 0 & 360 & 17 \\
& Costela marinada & Refrigeração & 664 & 32 \\
& Hot dog Frankfurter & $4(\mathrm{AM})$ & $560-600$ & 50 \\
Yersinia enterocolitica & Carne de boi & 25 & 110 & 17 \\
& Carne moída bovina & 25 & 195 & 15 \\
& Carne moída bovina & -30 & 388 & 15 \\
& Peixe & $0-2$ & $90-100$ & 33 \\
\hline
\end{tabular}

*AM - atmosfera modificada

Esporos e bactérias produtoras de esporos (Tabela 2), como o Clostridium botulinum, são geralmente mais resistentes à irradiação do que células vegetativas e bactérias não produtoras de esporos. Bactérias gram negativas são mais sensíveis do que as gram positivas e algumas espécies são capazes de reparar rapidamente o DNA danificado, sendo mais resistentes à irradiação do que as demais (JAY, LOESSNER e GOLDEN, 2005; FELLOWS, 2006; FRANCO e LANDGRAF, 2008).

A radiação de alimentos, visando a inativação de micro-organismos, pode ser dividida em radapertização, radicidação e radurização (JAY, LOESSNER e GOLDEN 2005; FELLOWS, 2006). Utiliza-se a radapertização quando se deseja a esterilização do alimento. Embora seja possível tal esterilização, a dose necessária é superior ao limite de 10 KGy permitido. É necessária dose de 42,72 KGy para se obter redução de $12 \mathrm{D}$ de esporos de Clostridium botulinum em carne de frango e para reduzir 12 ciclos logarítmicos de células vegetativas de Clostridium botulinum em carne cozida seria necessária dose de 16,8 KGy (Tabela 2). Entretanto, dose tão alta alteraria drasticamente as características sensoriais da carne, diminuindo significativamente sua aceitação sensorial. Por essa razão, a radapertização é pouco utilizada comercialmente, com exceção dos temperos e especiarias, frequentemente contaminados por bactérias esporulantes termorresistentes, que podem ser esterilizadas com doses entre 8 KGy a 10 KGy (JAY, LOESSNER e GOLDEN, 2005; FELLOWS, 2006).

A radicidação consiste na redução de patógenos não formadores de esporos. Nesse processo são utilizadas doses menores que na radapertização, uma vez que bactérias causadoras de toxinfecções alimentares são menos resistentes à irradiação do que micro-organismos esporulantes (JAY, LOESSNER e GOLDEN, 2005; FELLOWS, 2006). Conforme a Tabela 2, patógenos como Salmonella, Escherichia coli e Staphylococcus aureus são menos resistentes à radiação do que Clostridium botulinum e doses entre 3 KGy e 10 KGy são suficientes para inativá-los. Santos et al. (2003) constataram que a dose de 3,8 KGy de radiação gama (cobalto 60) é suficiente para garantir a segurança de sobrecoxas de frango em relação à presença de Salmonella typhimurium.

No processo de radurização são aplicadas doses relativamente baixas, entre 0,75 a 2,5 KGy, visando determinada redução do número de leveduras, fungos e bactérias não esporulantes para aumentar a vida-de-prateleira do produto (JAY, LOESSNER e GOLDEN, 2005; FELLOWS, 2006).

Miyagusku et al. (2003) efetuaram avaliação microbiológica e sensorial da vida útil de cortes de peito de frango submetidos à radiação gama (cobalto 60). Verificaram que a dose máxima de 3,0 KGy mostrou-se ideal para estender a vida útil de filés de frango refrigerados, aumentando-a de 5 dias (filé não irradiado e refrigerado) para 22 dias, sem comprometer de forma acentuada as características sensoriais do produto.

\subsection{EFEITO SOBRE O VALOR NUTRICIONAL E AS CARACTERÍSTICAS SENSORIAIS DO ALIMENTO}

A dose de irradiação que inativa micro-organismos também pode causar, mediante reações 
secundárias, alterações sensoriais indesejáveis no alimento. A água do alimento irradiado sofre radiólise, formando radicais livres que reagem entre si e com outras moléculas, gerando aroma e sabor desagradáveis. A irradiação em anaerobiose ou abaixo da temperatura de congelamento é menos nociva aos micro-organismos, porém diminui alterações de sabor e aroma indesejáveis nos alimentos. Em anaerobiose, a formação de peróxido é minimizada e em temperaturas abaixo do congelamento ocorre redução da radiólise (FRANCO e LANDGRAF, 2008).

Realizando o processo de irradiação em temperatura ambiente e na presença de oxigênio, Moda et al. (2010) verificaram que a irradiação de abacaxi nas doses de 1 KGy e 2 KGy acarretou menores notas nas avaliações sensoriais (atributos aroma, sabor, textura e aparência) em relação à amostra de abacaxi não irradiada. Oliveira et al. (2006) constaram que a utilização da irradiação, em doses de 0,3 KGy, 0,6 KGy e 0,9 KGy, não comprometeu a impressão global, a intenção de compra e os atributos sensoriais de aparência, aroma, textura e sabor de goiaba branca, variedade Kumagai, durante 21 dias de armazenamento sob refrigeração.

No geral, o processo de irradiação não causa grandes alterações na aparência dos alimentos e em alguns casos sua utilização pode ser favorável. Costa Neto, Spoto e Domarco (1997) verificaram que a utilização da irradiação, em doses de 8 KGy e 10 KGy, inibiu o escurecimento enzimático da mandioca em até 9 dias de armazenamento, enquanto que a mandioca não irradiada apresentou sinais de escurecimento já no segundo dia de armazenamento.

De acordo com Fellows (2006), a utilização de doses de radiação acima das comerciais pode quebrar o grupo sulfidrila de aminoácidos sulfúricos nas proteínas, provocando alterações no aroma e no sabor dos alimentos. Franco e Landgraf (2008) afirmaram que os aminoácidos com anel aromático sofrem alterações por serem mais sensíveis do que os demais.

Alterações de aroma e sabor também podem ocorrer devido ao efeito da irradiação nos lipídios do alimento. De forma semelhante ao processo de auto oxidação ocorre a produção de hidroperóxidos que irão gerar aromas e sabores desagradáveis (FELLOWS, 2006), principalmente quando a irradiação ou armazenamento subsequente for realizado na presença de oxigênio (FRANCO e LANDGRAF, 2008). Esse efeito pode ser minimizado com a irradiação de alimentos congelados, entretanto, não se recomenda a irradiação de alimentos com alto teor de lipídios (FELLOWS, 2006).

Em carnes, a ocorrência de odores estranhos se deve à produção de compostos voláteis como hidrocarbonetos, carbonilas e compostos contendo enxofre em sua molécula, entre outros (FRANCO e LANDGRAF, 2008).

Os carboidratos sofrem hidrólise e oxidação gerando compostos mais simples, mas sem alterar seu valor nutricional. Já as vitaminas apresentam variada sensibilidade quanto à irradiação, dependendo de fatores como a dose recebida, o tipo e o estado físico do alimento (FELLOWS, 2006). Já foram constatadas perdas no teor de tiamina, piridoxina, biotina e B12 e aumento no teor de riboflavina, ácido pantotênico e ácido fólico, provavelmente, devido à liberação de vitaminas a elas ligadas (FRANCO e LANDGRAF, 2008).

lemma et al. (1999) observaram significativa diminuição no teor de ácido ascórbico de suco de laranja em função do aumento da dose de radiação e do tempo de armazenamento. Santos (2008) também verificou diminuição significativa no teor de vitamina C e de carotenoides totais em função do aumento da dose de irradiação gama em amostras de pequi. Segundo Klein (1987), a perda da estabilidade do ácido ascórbico ocorre devido a fatores como o rompimento celular por dano ao tecido, moedura ou corte. Entretanto, de acordo com Fellows (2006), a irradiação em doses comerciais não causa maiores alterações sensoriais e nutricionais que os outros métodos de conservação de alimentos.

\section{CONCLUSÃO}

A radiação ionizante constitui promissora técnica de processamento não térmica aplicada em vários segmentos industriais, da agricultura, da medicina e da ciência, com diversos propósitos. 
Destaca-se sua utilização em vasta gama de alimentos visando inativar micro-organismos, retardar o amadurecimento, o envelhecimento ou brotamento de vegetais e para desinfestar frutas e hortaliças. Desde que doses adequadas sejam administradas, pode-se obter alimentos seguros e com características sensoriais e nutricionais mais próximas do natural em relação aos tratados termicamente. Suas principais limitações na conservação de alimentos envolvem o alto custo inicial e o fato das doses de irradiação recomendadas para alimentos não serem suficientes para a inativação enzimática.

Apesar de já ter sido comprovada a segurança da aplicação da energia ionizante em alimentos, ser permitida sua utilização em diversos países e ser cientificamente aceita como excelente método de conservação de alimentos, o progresso do seu uso comercial tem sido lento face às interpretações errôneas dos consumidores e à falta de informações sobre o uso dessa tecnologia.

\section{ABSTRACT \\ FOOD CONSERVATION BY IONIZING ENERGY: A REVIEW}

Was carried out a literature review about the use of ionizing radiation in the preservation of food. Were addressed topics such the historical evolution of the ionizing radiation in food, the principle of operation of the equipments, its different application areas, and especially its use in food preservation. Results of studies are presented with the objective of verifying the efficiency of ionizing radiation in the elimination of many different microorganisms in foods, and its effect on the sensory and nutritional characteristics of food. Despite the application of the ionizing radiation in food has been confirmed, and its use being allowed in several countries and scientifically accepted as an excellent method of food preservation, progress in its commercial is still slow, due to wrong interpretation of consumers and lack of information about the use of this technology.

KEY-WORDS: FOOD PRESERVATION; IONIZING RADIATION; NON-THERMAL TREATMENT.

\section{REFERÊNCIAS}

1 ARAÚJO, E. B.; LAVINAS, T.; COLTURATO, M. T.; MENGATTI, J. Garantia da qualidade aplicada à produção de radiofármacos. Brazilian Journal of Pharmaceutical Science, v. 44, n. 1, p. 1-12, 2008.

2 ASHBAUGH, C.E. Radioactiveand radiationtreatedgemstones. Radioactivity and Radiochemistry,v. 2, n. 1, p. 42-56, 2011.

3 BRASIL. Agência Nacional de Vigilância Sanitária (ANVISA). RDC no 21, de 26 de janeiro de 2001. Aprova o Regulamento técnico para irradiação de alimentos. Diário Oficial [da] República Federativa do Brasil, Brasília, DF, 26 jan. 2001. Disponível em: <http://www.anvisa.gov.br/legis/resol/21_01rdc.htm>. Acesso em: 12 de setembro de 2011.

4 BRASIL. Ministério da Ciência, Tecnologia e Inovação. Instituto de Energia Nuclear (IEN). Radiação gama é usada na preservação do patrimônio brasileiro. 2005. Disponível em: <www.ien.gov.br/noticias/noticias_arquivo/ radgama_010305.pdf>. Acesso em: 12 de setembro de 2011.

5 BRASIL. Ministério da Saúde. Instituto Nacional do Câncer. Ações de enfermagem para o controle do câncer: uma proposta de integração ensino-serviço. 3 ed. rev. atual. amp. Rio de Janeiro, 2008.

6 CARDOSO, V. M. Aplicação da radiação de feixe de elétrons como pré-tratamento do bagaço da cana-de-açúcar para hidrólise enzimática da celulose. 2008. 69 p. Dissertação (Mestrado em Ciências) - Instituto de Pesquisas Energéticas e Nucleares, São Paulo, 2008.

7 CENTRO DE ENERGIA NUCLEAR NA AGRICULTURA (CENA). Irradiação de alimentos. Disponível em: <www.cena. usp.br>. Acesso em: 30 de julho de 2011.

8 CHIRINOS, R. R. O.; VIZEU, D. M.; DESTRO, M. T.; FRANCO, B. D. G. M.; LANDGRAF, M. Inactivation of Escherichia coli O157:H7 in hamburgers by gamma irradiation. Brazilian Journal of Microbiology, v. 33, n. 1, p. 53-56, 2002.

9 CHMIELEWSKI, A. G.; HAJI-SAIED, M.; AHMED, S. Progress in radiation processing of polymers. Nuclear Instruments and Methods in Physics Research B, v. 236, p. 44-54, 2005.

10 CLAVERO, M. R. S. et al. Inactivation of Escherichia coli O157:H7, Salmonellae, and Campylobacter jejuni in raw ground beef by gamma irradiation. Appl. Environ. Microbiol., v. 60, p. 2069-2075, 1994.

11 CLOUGH, R. L. High-energy radiation and polymers: a review of commercial processes and emerging applications. Nuclear Instruments and Methods in Physics Research B, v. 185, p. 8-33, 2001. 
12 COMISSÃO NACIONAL DE ENERGIA NUCLEAR (CNEN). Pesquisa. Disponível em: <http://www.cnen.gov.br/pesquisa/ pesquisa.asp>. Acesso em: 14 de novembro de 2012.

13 COSTA NETO, P. R.; SPOTO, M. H. F.; DOMARCO, R. E. Uso da radiação gama na inibição do escurecimento de mandioca (Manihot utilissima Pohl) in natura, sem casca. Boletim do CEPPA, v. 15, n. 1, p. 75-83, 1997.

14 DIEHL, J. F. Food irradiation - past, present and future. Radiation Physics and Chemistry, v. 63, p. 211-215, 2002.

15 ELZAWAHRY, Y. A.; ROWLEY, D. B. Radiation resistance and injury of Yersinia enterocolitica. Applied and Environmental Microbiology, v. 37, p. 37-50, 1979.

16 FAO/IAEA. Food Agriculture Organization. International Atomic Energy Agency. Division of Nuclear Techniques in Food and Agriculture. Food \& Environmental Protection Newsletter, v. 14, n. 1, p. 36, 2011.

17 FELLOWS, P.J. Tecnologia do processamento de alimentos: princípios e prática. 2.ed. PortoAlegre:Artmed, 2006. 602 p.

18 FOLLETTI, P. A.; ARMSTRONG, J. W. Revised irradiation doses to control melon fly, mediterranean fruit fly, and oriental fruit fly (Diptera: Tephritidae) and a generic dose for tephritid fruit flies. Journal of Economic Entomology, v. 97, n. 4, p. 1254-1262, 2004.

19 FRANCO, B. D. G. M.; LANDGRAF, M. Microbiologia dos Alimentos. São. Paulo: Ed. Atheneu, 2008.182 p.

20 GRANDISON, A. S. Irradiation. In: BRENNAN, J. G. (Ed). Food processing handbook. Weinheim: WILEY-VCH Verlag, 2006. p. 147-171.

21 GIOVEDI, C.; MACHADO, L. D. B.;AUGUSTO, M.; PINO, E. S.; RADINO, P. Evaluation of the mechanical properties of carbon fiber after electron beam irradiation. Nuclear Instruments and Methods in Physics Research B, v. 236, p. 526-530, 2005.

22 GOULARTE, L.; MARTINS, C. G.; MORALES-AIZPURÚA, I. C.; DESTRO, M. T.; FRANCO, B. D. G. M.; VIZEU, D. M.; HUTZLER, B. W.; LANDGRAF, M. Combination of minimal processing and irradiation to improve the microbiological safety of lettuce (Lactuca sativa, L.). Radiation Physics and Chemistry, v. 71, p. 155-159, 2004.

23 GÜRSEL, B.; GÜRAKAN, G. C. Effects of gamma irradiation on the survival of Listeria monocytogenes and on its growth at refrigeration temperature in poultry and red meat. Poultry Science, v. 76, p. 1661-1664, 1997.

24 HERNANDES, N. K.; VITAL, H. C.; SABAA SRUR, A. U. O. Irradiação de alimentos. Boletim SBCTA, v. 37, n. 2, p. 154$159,2003$.

25 HUHTANEN, C. N.; JENKINS, R. K.; THAYER, D. W. Gamma radiation sensitivity of Listeria monocytogenes. Journal of Food Protection, v. 9, p. 610-613, 1989.

26 IEMMA, J.; ALCARDE, A. R.; DOMARCO, R. E.; SPOTO, M. H. F.; BLUMER, L.; MATRAIA, C. Radiação gama na conservação do suco natural de laranja. Scientia Agricola, v. 56, n. 4, p. 1193-1198, 1999.

27 INSTITUTO DE PESQUISA ENERGÉTICAS E NUCLEARES (IPEN). Hidrogeis. 2012a. Disponível em: <http://www. ipen.br/sitio/?idc=228>. Acesso em: 12 de novembro de 2012.

28 INSTITUTO DE PESQUISA ENERGÉTICAS E NUCLEARES (IPEN). Radioesterilização. 2012b. Disponível em: <http:// www.ipen.br/sitio/index.php?idm=253>. Acesso em: 12 de novembro de 2012.

29 INSTITUTO DE PESQUISA ENERGÉTICAS E NUCLEARES (IPEN). Radioesterilização para banco de tecidos biológicos. 2012c. Disponível em: <http://www.ipen.br/sitio/?idc=240>. Acesso em: 12 de novembro de 2012.

30 JAY, J. M.; LOESSNER, M. J.; GOLDEN, D. A. Radiation protection of foods and nature of microbial radiation resistance. In: JAY, J. M.; LOESSNER, M. J.; GOLDEN, D. A. (Eds.). Modern food microbiology. $7^{\text {th }}$ ed. New York: Springer, 2005. p. 371-390.

31 JO, C.; KIM, H. J.; KIM, D. H.; LEE, W. K.; HAM, J. S.; BYUN, M. W. Inactivation of foodborne pathogens in marinated beef rib by ionizing radiation. Food Control, v. 18, p. 859-865, 2007.

32 JO, C.; LEE, N. Y.; KANG, H. J.; SHIN, D. H.; BYUN, M. W. Inactivation of foodborne pathogens in marinated beef rib by ionizing radiation. Food Microbiology, v. 21, p. 543-548, 2004.

33 KAMAT, A.; THOMAS, P. Radiation inactivation of some food-borne pathogens in fish as influenced by fat levels. Journal of Applied Microbiology, v. 84, p. 478-484, 1988.

34 KHATTAK, A. B.; BIDI, N.; CHAUDRY, M. A.; MISAL KHAN; MAAZULLAH KHAN; QURESHI, M. J. Shelf life extension of minimally processed cabbage and cucumber through gamma irradiation. Journal of Food Protection, v. 68, n. 1, p. 105-110, 2005.

35 KLEIN, B. P. Nutritional consequences of minimal processing of fruits and vegetables. Journal of Food Quality, Westport, v. 10 , p. $179-193,1987$. 
36 LEONEL, F. R. Irradiação e qualidade da carne de frango congelada e embalada a vácuo. 2008. 74 p. Tese (Doutorado em Zootecnia) - Faculdade de Ciências Agrárias e Veterinárias, Universidade Estadual Paulista, Jaboticabal, 2008.

37 MIYAGUSKU, L.; CHEN, F.; LEITÃO, M. F. de F.; BAFFA, O. Avaliação microbiológica e sensorial da vida-útil de cortes de peito de frango irradiados. Ciência e Tecnologia de Alimentos, v. 23 supl., p. 7-16, 2003.

38 MODA, E. M.; PILON, L.; ZOCCHI, S. S.; SPOTO, M. H. F. Qualidade físico-química e sensorial de abacaxi minimamente processado e irradiado. Boletim do CEPPA, v. 26, n. 2, p. 267-276, 2008.

39 MOSTAFAVI, H. A.; MIRMAJLESSI, S. M.; FATHOLLAHI, H. The potential of food irradiation: benefits and limitations. In: ELISSA, A. H. A. (Ed.). Trends in vital Food and control engineering. Rijeka: InTech, 2012. p.43-68.

40 MOY, J.H.; KANESHIRO, K.Y.; OHTA, A.T.; NAGAI, N.Y. Radiation disinfestation of California stone fruits infested by Medfly: effectiveness and fruit quality. Journal of Food Science, Chicago, v. 48, n. 3, p. 928-934, 1983.

41 NIEMIRA, B. A. Radiation sensitivity and recoverability of Listeria monocytogenes and Salmonella on 4 lettuce types. Journal of Food Science, v. 68, n. 9, p. 2784-2787, 2003.

42 OlIVEIRA, A. C. G.; ZANÃO, C. F. P.; ANICETO, A. P. P.; SPOTO, M. H. F.; CANNIATTI-BRAZACA, S. G.; WALDER, J. M. M. Conservação pós-colheita de goiaba branca kumagai por irradiação gama: aspectos físicos, químicos e sensoriais. Boletim do CEPPA, v. 24, n. 2, p. 375-396, 2006.

43 ORNELLAS, C. B. D.; GONÇALVES, M. P. J.; SILVA, P. R.; MARTINS, R. T. Atitude do consumidor frente à irradiação de alimentos. Ciência e Tecnologia de Alimentos, v. 26, n. 1, p. 211-213, 2006.

44 OSAILI, T. M.; SHAKER, R. R.; ABU AL-HASAN, A. S.; AYYASH, M. M.; MARTIN, E. M. Inactivation of Enterobacter sakazakii in infant milk formula by gamma irradiation: determination of D10-value. Journal of Food Science, v. 72 , n. 3 , p. 85-88, 2007

45 PINO, E. S.; GIOVEDI, C. Radiação ionizante aplicada ao processamento de polímeros. Revista UNILUS Ensino e Pesquisa, v. 3, n. 5, p. 7-10, 2006.

46 PINO, E. S.; GIOVEDI, C. Radiação ionizante e suas aplicações na indústria. Revista UNILUS Ensino e Pesquisa, v. 2 , n. 2, p. 47-51, 2005.

47 SANTOS, A. F.; VIZEU, D. M.; DESTRO, M. T.; FRANCO, B. D. G. M.; LANDGRAF, M. Determinação da dose de radiação gama para reduzir a população de Salmonella spp em carne de frango. Ciência e Tecnologia de Alimentos, v. 23, n. 2, p. 200-205, 2003.

48 SANTOS, M. R. L. Efeitos da radiação gama do cobalto 60 em frutos de pequi (Caryocar brasiliense Camb.). 2008.92 p. Tese (Doutorado em Ciências) - Centro de Energia Nuclear na Agricultura, Universidade de São Paulo, Piracicaba, 2008.

49 SERRANO, L. E.; MURANO, E. A.; SHENOY, K.; OLSON, D.G. D values of Salmonella enteritidis isolates and quality attributes of shell eggs and liquid whole eggs treated with irradiation. Poultry Science, v. 76, n. 1, p. 202-206, 1997.

50 SOMMERS, C. H.; BOYD, G. Radiation sensitivity and postirradiation growth of foodborne pathogens on a ready-to-eat Frankfurter on a roll product in the presence of modified atmosphere and antimicrobials. Journal of Food Protection, v. 69, n. 10 , p. $2436-2440,2006$.

51 SPOTO, M. H. F:; GALLO, C. R.; ALCARDE, A. R.; GURGEL, M. S. A.; BLUMER, L; WALDER, J. M. M.; DOMARCO, R. E. Gamma irradiation in the control of pathogenic bacteria in refrigerated ground chicken meat. Scientia Agricola, v. 57 , n. 3, p. 389-394, 2000.

52 STEFANOVA, R.; VASILEV, N. V.; SPASSOV, S. L. Irradiation of food, current legislation framework, and detection of irradiated foods. Food Analytical Methods, v. 3, p. 225-252, 2010.

53 SVIZZERO, D. P. As múltiplas facetas do diamante. Revista USP, São Paulo, n. 71, p. 52-69, 2006.

54 THAYER, D. W.; BOYD, G. Elimination of Escherichia coli 0157:H7 in meats by gamma irradiation. Applied and Environmental Microbiology, v. 59, p. 1030-1034, 1993.

55 VITTI, D. M. S. S.; DEL MASTRO, N. L.; KIKUCHI, O. K.; NOGUEIRA, N. L. Irradiação de resíduos fibrosos com feixe de elétrons: efeitos na composição química e digestibilidade. Scientia Agricola, v. 55, n. 2, p. 159-171, 1998.

56 WHO. World Health Organization. Wholesomeness of irradiated food. Geneva, 1981. 36 p. (Technical Report Series, 659).

57 WHO. World Health Organization. High dose irradiation: wholesomeness of food irradiated with doses above 10 kGy. Geneva, 1999. 204 p. (Technical Report Series, 890).

58 ZHONG, K.; HU, X.; ZHAO, G.; CHEN, F.; LIAO, X. Inactivation and conformational change of horseradish peroxidase induced by pulsed electric field. Food Chemistry, v. 92, p. 473-479, 2005. 